\title{
ESTÉTICA DE LA NOVELA EN ESPAÑA. TRES MOMENTOS: ORTEGA, BERGAMÍN Y MARIANO BAQUERO GOYANES
}

\author{
LUIS BELTRÁN ALMERÍA \\ Universidad de Zaragoza
}

\section{RESUMEN}

La aportación española a la teoría de la novela es, a juicio del autor, la aportación más importante a la teoría literaria que se ha hecho desde España en el siglo XX. Esa aportación sigue una línea de continuidad cuyos eslabones fundamentales son Ortega, Bergamín y Mariano Baquero Goyanes. La contribución de Ortega es la más reconocida aunque ese reconocimiento sea superior en Norteamérica que en España. Las aportaciones de Bergamín y Baquero Goyanes no han salido hasta la fecha del ámbito de lo hispánico e incluso aquí son mal conocidas, sobre todo la de Bergamín.

Palabras clave: novela, teoría de la novela, Ortega, Bergamín, Baquero.

\section{AESTHETICS OF THE NOVEL IN SPAIN. THREE PHASES: ORTEGA, BERGAMÍN AND MARIANO BAQUERO GOYANES}

\begin{abstract}
Spanish theory of the novel is, in the opinión of the author, the most important contribution to the literary theory made from Spain during the 20th century. This contribution follows a continuity whose fundamental links are Ortega, Bergamín y Mariano Baquero Goyanes. Ortega's theory of the novel is the most known of the three, although it recognition is superior in USA than in Spain. The contributions by Bergamín and Baquero Goyanes have not gone beyond, so far, the nacional limits and, even in Spain, they are not very well known.
\end{abstract}

Key Words: novel, theory of the novel, Ortega, Bergamín, Baquero Goyanes.

Quizá no se haya valorado debidamente la aportación española a la teoría de la novela. La dimensión más valiosa de esa aportación es una estética de la novela que no desmerece de la gran teoría de la novela a escala europea (la de autores como Lukács o Bajtín) y que, en ciertos momentos, consigue ir un poco más allá. Desde «La agonía de la novela» de Ortega a los escritos de Mariano Baquero Goyanes, pasando por el ensayo visionario de José Bergamín, puede percibirse una línea de continuidad que subraya el papel de la 
forma artística para comprender la novela, frente a las tentaciones simplistas del contenidismo culturalista o del formalismo retórico. Vinculada a esa orientación a la forma estética de estos pensadores aparece su profunda estima por la obra de Dostoievski, hecho que quizás no sea casual.

Ciertamente no son Ortega, Bergamín y Baquero los únicos españoles que han hecho aportaciones al estudio de la novela, pero sí que son los que las han hecho desde una posición tal que sus propuestas todavía siguen teniendo futuro en el siglo XXI. Otras, aun teniendo una trascendencia histórica, como las de Pío Baroja y Marcelino Menéndez Pelayo, quizá carezcan de esa proyección y han quedado como documentos de una forma de pensar caducada.

\section{ORTEGA Y LA AGONÍA DE LA NOVELA}

En la vasta obra de Ortega, dos momentos se destacan en lo que respecta a la novela. El primero llevó inicialmente el título de «La agonía de la novela» y fue escrito en 1912. Apareció más tarde como «Meditación primera» de las Meditaciones del Quijote ${ }^{1}$. El segundo aparece en 1925 como Ideas sobre la novela (que en ese año formó un libro con La deshumanización del arte). Entre ambos escritos hay una distancia mayor de la que cabe esperar en poco más de una década.

Vayamos en primer lugar con «La agonía de la novela.» Ortega intenta elaborar una síntesis teórica de la novela que es, a la vez, una filosofía de la historia literaria. Aunque su epicentro no alcanza un gran nivel, hay un número considerable de afirmaciones valiosas y, en especial, su punto de partida es que sólo comprendiendo el mito y géneros tradicionales como la epopeya, podremos entender el sentido de la novela, por oposición. Novela y épica son justamente lo contrario. Derivar a aquella de esta es, para Ortega, cerrarnos el camino para comprender las vicisitudes del género novelesco. Lo que el lector del s. XIX buscaba en la novela no tiene nada que ver con lo que buscaban los antiguos en la epopeya $(1988,199)$. El tema de la épica es el pasado ideal, la absoluta antigüedad. El arcaísmo es la forma literaria de la épica, el instrumento de poetización $(1988,201)$. Y, su tiempo, es el pasado absoluto. Nuestro tiempo es, respecto a ese pasado, una segunda etapa de la vida cósmica, una realidad sucedánea y decaída $(1988,202)$. Además de esa frontera temporal, Ortega afirma el carácter tradicional de la epopeya. Homero no pretende contar nada nuevo. Lo que él cuenta lo sabe ya el público, y Homero sabe que lo sabe $(1988,203)$. Las figuras épicas no son representantes de

\footnotetext{
${ }^{1} \mathrm{Al}$ parecer, estas meditaciones fueron pensadas por Ortega como «salvaciones». Esta rectificación es un síntoma del giro orteguiano desde una posición contestataria y modernista a otra más centrada y realista. Al mismo tiempo parece producirse el abandono del programa de la manera española de ver las cosas por otra perspectiva más mundana y menos nacionalista.
} 
tipos, sino criaturas únicas. La épica es realización plena de aquellos sereshéroes que nada tienen que ver con el hombre y el personaje de nuestro tiempo. Las figuras épicas no son representantes de tipos, sino criaturas únicas. La épica es realización plena de aquellos seres-héroes, que nada tienen que ver con el hombre y el personaje actuales. Ideas semejantes aparecen en el estudio de Bajtín «Épica y novela,» escrito en los años cuarenta y publicado en los setenta, y se fundan en las enseñanzas de Wilamowitz.

Sin embargo, la idea de que la novela ha de comprenderse como la lucha entre la novela de imaginación (aventuras) y la novela realista (la del proceso) no está a la altura del planteamiento desplegado. La dinámica de la novela se explica a partir de la trayectoria de dos direcciones: una ingenua y rectilínea; otra irónica, oblicua... La novela de aventuras, el cuento, la épica son aquella manera ingenua de vivir las cosas imaginarias y significativas. La novela realista es esta segunda manera oblicua. Necesita, pues, de la primera (1988, 216). Este dualismo ha sido muy común en el pensamiento sobre la novela contemporáneo. Es una actitud convencional que cree comprender el universo de la novela repartiéndolo en dos vertientes, la exterior (aventurera) y la interior (formativa, espiritual). En nuestros días, Thomas Pavel ha insistido en esta vía. Incluso en Bajtín encontramos la teorización sobre dos líneas estilísticas de la novela, cuyas trayectorias se parecen a las diseñadas por Ortega.

La articulación entre ambas vertientes de la novela la concibe Ortega en clave de decadencia. Al perder la épica su influjo religioso, toma a campo traviesa en busca de aventuras $(1988,208)$. La aventura quiebra como un cristal la opresora, insistente realidad. Es lo imprevisto, lo impensado, lo nuevo. Cada aventura es un nuevo nacer del mundo, un proceso único (1988, 210). En esta trayectoria cadencial juega un papel decisivo el Quijote. Para la estética es esencial ver la obra de Cervantes como una polémica contra las caballerías que da paso al realismo $(1988,213)$. Don Quijote... es una naturaleza fronteriza, como lo es, en general, según Platón, la naturaleza del hombre (1988, 214).

La tendencia realista es la que necesita más justificación y explicación. La realidad entra en la poesía para elevar a una potencia estética más alta la aventura. Aunque la novela realista haya nacido como oposición a la llamada novela imaginaria, lleva dentro de sí infartada la aventura $(1988,215)$. La novela realista trata de un proceso inverso al que engendra la novela de imaginación. La novela realista describe el proceso mismo, y aquella sólo el objeto producido: la aventura $(1988,217)$. Ortega añade un vaticinio sorprendente: la novela del siglo XIX será ilegible muy pronto: contiene la menor cantidad posible de dinamismo poético $(1988,233)$.

La concepción orteguiana del realismo dista bastante del concepto convencional. Según Ortega, cuando los modernos buscamos la realidad buscamos las apariencias, lo actual. Para los griegos, en cambio, realidad es lo esencial 
(1988, 204). El tema de la novela es la actualidad. Los personajes son típicos y extrapoéticos. El arte literario no se limita a la poesía. El arte es la técnica, es el mecanismo de realización. Y la novela y el realismo prueban esto (1988, 206). El germen del realismo se halla en un cierto impulso que lleva al hombre a imitar lo característico de sus semejantes o animales. El que imita, imita para burlarse. Aquí tenemos el origen que buscamos: el mimo. Sólo, pues, con motivo de una intención cómica parece adquirir la realidad un interés estético. Como más tarde hiciera Cervantes, Aristófanes echa mano de las gentes que roza en las plazuelas y las introduce dentro de la obra artística. Pero es para burlarse de ellas. El diálogo de Platón también describe lo real y también se burla de lo real. Cuando trasciende lo cómico es que se apoya en un interés extrapoético —el científico. Jamás encontramos la poesía de lo real como simplemente real. Esta explicación del realismo introduce dos aspectos que, por desgracia, Ortega no desarrolló. Uno es una teoría de la escisión entre lo serio y la risa. El otro apunta hacia una teoría del simbolismo. Esa teoría del simbolismo parece germinar a partir de dos momentos: la observación de los límites del realismo y la pervivencia de la épica. Su observación sobre la falta de poesía de la novela realista y su interés por los hechos conlleva esa reivindicación en germen del simbolismo ${ }^{2}$.

Quizá el momento culminante de esta primera intervención orteguiana sobre la novela resida en la teoría estética que incorpora. Esta teoría se funda en el concepto de forma artística. Los géneros literarios son verdaderas categorías estéticas, ciertos temas irreductibles entre sí $(1988,196)^{3}$. Claro que por géneros parece entender categorías más amplias de las convencionales de la historia literaria. Esas categorías son la épica, el lirismo, el heroísmo, la tragedia, el realismo y la novela.

La perspectiva épica lleva hasta nosotros. No morirá nunca. Los motivos épicos, «hacinados en la memoria literaria, escondidos en el subsuelo de la reminiscencia popular, constituyen una levadura poética de incalculable energía. Acercad la historia verídica ... a estas materias incandescentes.» La novela griega no es más que historia corrompida, divinamente corrompida por el mito, por esos motivos épicos $(1988,207)$. La literatura de imaginación, mítica, prolongará sobre la humanidad hasta el fin de los tiempos el influjo bienhechor de la épica, que fue su madre $(1988,208)$. El mito es siempre el punto de partida de toda poesía, inclusive de la realista. Sólo que en ésta acompañamos al mito en su descenso, en su caída. El tema de la poesía realista es el desmoronamiento del mito $(1988,219)$.

\footnotetext{
${ }^{2}$ Ortega ve el realismo como un producto decimonónico. «El ideal del siglo XIX era el realismo. «Hechos, sólo hechos» — clama el personaje dickensiano de Tiempos difíciles», 1988, 234.

${ }^{3}$ La fórmula ciertos temas irreductibles entre sí parece recordar otra fórmula de Leibniz: rerum originatione radicali, que Ortega utiliza para plantear su objetivo de alcanzar la realidad radical de la vida humana.
} 
El lirismo es, frente a la épica, el otro manantial de la poesía. El lirismo es una proyección estética de la totalidad general de nuestros sentimientos. La épica no es ni triste ni alegre: es un arte apolíneo, indiferente, todo él formas de objetos eternos, sin edad, extrínseco e invulnerable.

Épica y novela parecen comprenderse, desde el punto de vista orteguiano, en un ámbito superior: el heroísmo. «Ser héroe consiste en ser uno, uno mismo» (1988, 223). Épica y novela, en cambio, discrepan por sus objetos —el pecado y la realidad- $(1988,223)$. El heroísmo, unas veces se le ha mirado rectamente y otras oblicuamente $(1988,224)$. En el primer caso, convierte al héroe en un objeto estético que llamamos lo trágico. En el segundo, hace de él un objeto estético que llamamos lo cómico. El siglo XIX se ha inclinado con exceso a ver la comedia sobre la tierra.

La raiz de lo heroico hállase en un acto real de voluntad. La voluntad es el tema trágico. Lejos, pues, de originarse en la fatalidad lo trágico, es esencial al héroe querer su trágico destino $(1988,227)$. La tragedia griega no la entendemos bien desde una perspectiva moderna (1988, 225). Sin embargo, la lectura que Ortega hace de Esquilo es esencialmente moderna. «Yo lo llamaría teopoeta. Le acongojan los problemas del bien y del mal, de la libertad, de la justificación, del orden en el cosmos, del causante de todo» (1988, 226). Esta lectura bien puede trasladarse al autor que para Ortega encarna mejor que ningún otro la esencia de lo moderno: Dostoievski.

La interpretación que hace Ortega de la comedia tiene también su dimensión sorprendente. La vis comica se limita a acentuar la vertiente del héroe que da hacia la pura materialidad $(1988,229)$. Pero añade: la comedia es el género literario de los partidos conservadores (1988, 230). El género novelesco es, sin duda, cómico. No digamos que humorístico, porque bajo el manto del humorismo se esconden muchas vanidades $(1988,231)$. La novela es tragicomedia, esta parece su conclusión. Y apela de nuevo a Platón. En Banquete (223 d) afirma que no dos hombres distintos sino uno mismo debía ser el poeta de la tragedia y de la comedia [el novelista]. Platón, alma llena de gérmenes, ponía aquí la simiente de la novela $(1988,232)$.

En 1925 vuelve Ortega con su meditación novelística. Incluso se refiere a la meditación de diez años antes. Pero el tono ahora es distinto. Estas ideas proceden de un debate con Baroja (Baroja respondió a una crítica orteguiana de Las figuras de cera con el prólogo de La nave de los locos). El tono general del nuevo ensayo se acerca más al nivel de la vieja preceptiva que al de la exposición de filosofía de la historia literaria que se respira en la primera meditación. Quizá la reivindicación del arte novelístico de Dostoievski (también el de Stendhal) sea el elemento más notable porque da cuerpo a lo que aquí venimos sugiriendo como teoría del simbolismo. «El realismo — llamémosle así para no complicar- de Dostoievski no está en las cosas y en los hechos, sino en el modo de tratar con ellos a que se ve obligado el lector. No es la materia de la vida lo que constituye su realismo sino la forma de la vida» 
(1982, 33-34). El espíritu preceptivo de este ensayo conlleva interesantes observaciones para el novelista. En especial, ésta: la penuria de temas de la novela actual exige una exquisita calidad; y, por eso, es tan grande hoy la distancia entre las buenas y las malas novelas. Esa distancia es la causa de que hoy sea posible conseguir «la obra perfecta» $(1982,51)$.

Los problemas que plantea la doble mirada de Ortega sobre la novela son muchos. Orringer entiende el «Breve tratado sobre la novela» (es decir, la meditación primera) como un diálogo y distanciamiento de Ortega con $\mathrm{H}$. Cohen. La distancia, en efecto, es mucha, aunque las alusiones también. Esa distancia la justifica Orringer por las lecturas, las fuentes. Esas fuentes serían Simmel (la aventura), Bergson (lo cómico), Immisch (la épica) y Friedemann (el narrador). Estas lecturas son reales (Orringer investigó la biblioteca y el epistolario de Ortega), pero no explican la dimensión trascendente de este escrito, que el mismo Orringer intuye pero no llega a comprender. Y tampoco explican las coincidencias de Ortega con Lukács y Bajtín. Orringer es consciente de sus limitaciones y llama a continuar la investigación con otros autores (apunta a Hartmann y a otros del círculo de Marburg). Pero Orringer también plantea la necesidad de reconocer que la obra representa un intento de síntesis de muchos textos ajenos dentro del marco de un sistema naciente (1979, 203-4).

Podemos concluir provisionalmente que Ortega abrió dos líneas de extraordinaria importancia para el pensamiento moderno, una relativa a la novela y la otra relativa a la estética moderna. Es verdad que no las profundizó y aun puede decirse que las abandonó. Es lástima que el pensamiento español posterior no las prosiguiera. Salvo las excepciones de Bergamín y de Baquero Goyanes nadie ha venido a tirar de estos hilos. Y la atención a Ortega en tanto pensador de la novela es hoy mayor en EE.UU que en España.

\section{JosÉ BERGAMÍN EN EL LABERINTO DE LA NOVELERÍA}

Bergamín aborda la novela desde un punto de vista hermético, apocalíptico diría él mismo. La primera frase de su ensayo es una declaración hermética: «Voy andando en la oscuridad». Su acercamiento se apoya en la retórica habitual de las revelaciones. Su primera definición de la novela insiste en ese camino: «La novela también es lo que va de ayer a hoy: un sueño entrañado en el laberinto de la sombra» $(1973,85)$.

Desde esta constatación, Bergamín se permite, en apariencia, ignorar la evolución histórica de la novela. Sólo «importa mucho... la maravilla humana de la novela, la sorpresa viva, novelesca, del hombre» $(1973,85)$. Bergamín equipara novela y hombre y concluye que: «lo que importa del hombre es su revelación eterna, que es su revolución permanente. El hombre siempre nuevo» $(1973,85)$. Desde esta perspectiva resulta muy difícil diferenciar la 
poesía de la novela. Lo mismo que dice de la novela le sirve a la poesía. La razón de esta indistinción es la doctrina hermética que profesa Bergamín. Para el hermetismo la frontera entre la prosa y la poesía es permeable. Las obras herméticas pasan con enorme facilidad de la poesía a la prosa y viceversa. Esa estética se funda en un discurso que se aplica tanto a un lado como al otro de los lenguajes literarios.

Sin embargo, algún tipo de caracterización se hace imprescindible para comprender la novela. Bergamín retoma tres argumentos:

1. La novela es el género más prolífico («¡cómo que no es género, es especie!»1973, 86).

2. La novela crea un mundo en cada novela. Ese mundo espera una respuesta de nuestra parte. Esa respuesta no necesita el asentimiento o la repulsa (como el amor y la poesía). La verdadera novela es la que se burla de la novelería. El Quijote es el ejemplo. Se escribió contra la novela de aventuras, contra el folletín, contra el cine $(1973,91)$.

3. La novela se presta a una concepción dualista que se describe en términos dinámicos y opuestos:

- La lucha entre lógicos y magos;

- las bodas del Cielo y el Infierno (siguiendo a Blake)

- dos mundos polares: Cervantes y Dostoievski, las dos máximas corrientes espirituales de toda la novelería del mundo (1973, 93).

Cervantes es definido como un mundo clarísimo, luminoso, transparente y superficial — profundamente superficial—. Las apariencias no engañan nunca en ese mundo novelesco teatral de las novelas de Cervantes (1973, 95). Con su obra explica la disolución de la frontera entre prosa y poesía. Cervantes suena mal, tanto en prosa como en poesía, porque lo milagroso de su palabra no reside en la musicalidad, sino en el poder pictórico de su plasticidad imaginativa, visual (1973, 94-95). La frontera entre novela y poesía se funda en los mundos respectivos: el mundo humano, para la novela, y el mundo divino, para la poesía. «El mundo de la novela acaba donde empieza el mundo de la poesía. El fin del mundo de la novela — su revelación- es el principio del mundo de la poesía» $(1973,98)$. Lo que no le impide afirmar que donde acaba el Quijote empieza el Persiles, pues esta obra trasciende lo novelístico a lo poético $(1973,99)$. Y Dostoievski es caracterizado como un mundo misterioso, sombrío, oscuro y profundo — superficialmente profundo- (1973, 92-93). Dostoievski culmina la novela romántica, dejando libre el monstruo de la novelería (104).

La gran diferencia que aprecia Bergamín entre Cervantes y Dostoievski (con Goethe en el medio) es que el novelista ruso culmina la novela moderna. La novela moderna parte de la degeneración de la novela clásica (que arranca con la novela romántica). «Se genera, monstruosa y laberíntica, por 
las causas que la corrompen: la historia, la psicología y la moral. Y el origen de esa corrupción está en la novela sentimental del siglo XVIII y en el «primoroso laberinto de amor ... de La Princesa de Clèves» (1973, 105). Sus herederos serán Stendhal, Victor Hugo, Sue, Balzac, Dickens, Flaubert, Zola, Tolstói, Galdós... ${ }^{4}$.

En su caracterización de la novela moderna, Bergamín constata que, para el novelista, no hay cuestión moral en la novela. Ha empezado por darle a sus personajes el vestido de bondad o de maldad que les convenía $(1973,112)$. Es Laclos en Las amistades peligrosas quien pone la semilla de la modernidad novelística, poniendo de manifiesto algo escandaloso: la mezcla del bien y del mal, la yuxtaposición del cielo y del infierno $(1973,114)$.

La culminación de la novela moderna es la obra de Dostoievski. De Dostoievski le llama la atención la centralidad del suceso. «Todo sucede. Se sucede, en el tiempo, de una manera visual, espacial; teatral, en suma: dramática» $(1973,129)$. Bajtín percibió este mismo fenómeno en la obra del novelista ruso y lo llamó simultaneidad. Bergamín lo explica en estos términos: «El novelista procede con obligada libertad al cortar el tiempo en el espacio, de este modo visual, teatral, para localizar su drama» $(1973,130)$.

$\mathrm{El}$ arte de Dostoievski consiste en dramatizar, teatralizar tan profundamente la novela: en alcanzar de toda la novelería del siglo XIX esta inesperada y magnífica conclusión.

Lo que llamaríamos la revelación de la voz, del espíritu subterráneo, puede que no haya sido más que eso: el darse cuenta Dostoievski de la situación infra-teatral en que la novela se encontraba a consecuencia de sus desviaciones estéticas (1973, 130-31).

El eje que une a Cervantes y Dostoievski es su pensamiento religioso y cristiano.

La estética de Bergamín es esencialmente hermética. Esto conlleva un pensamiento basado en categorías duales que tienden a la conjunción y al dramatismo. Como dice el propio Bergamín, la savia terrestre de la pasión humana enciende y riega el frondaje de los cielos $(1973,103)$.

Esta poderosa iluminación bergaminiana puede ser considerada a la vez como una réplica y una continuidad de la meditación ortegiana. Ortega tuvo también la tentación hermética. Ya hemos señalado que pensó en llamar salvaciones a lo que luego fueron meditaciones. Bergamín, que formó parte del

${ }^{4}$ La fuente de inspiración sobre la estética y la novela modernas de Bergamín es el postromántico francés Ernest Hello (1828-1885), católico y hermético como él. En Hello ve Bergamín una «estupenda paradoja»: la novela es el libro aburrido por excelencia $(1973,110)$ Con esto pretende decir que el gran tema de la novela moderna es un aburrimiento profundo: un abismo. La novela es el libro aburrido por ser el libro totalizador, unificador de la diversión $(1973,116)$, porque no hay nada que nos lleve más directamente al aburrimiento que la diversión. 
entorno de Ortega en los años treinta, se propone y alcanza una mayor radicalidad respecto al maestro. Su lectura de Dostoievski y del propio Cervantes es, si cabe, más provechosa. También habrá de pagar un peaje por esa radicalidad, el peaje del silencio. Su iluminación parece no haber tenido consecuencias.

\section{MARIANO BAQUERO GOYANES Y SUS VARIACIONES SOBRE UN MISMO TEMA}

No hay en la filología española nadie comparable en su dedicación tan completa a la novela y los géneros afines como Mariano Baquero Goyanes. Y, aunque dedicó una monografía a la novela - Qué es la novela- y varios libros a recoger estudios sobre la novela actual, su pensamiento acerca de este género está disperso por toda su obra, en especial en los artículos periodísticos y en otros artículos académicos. En la actualidad sus discípulos Abraham Esteve y Francisco Vicente Gómez preparan la edición de su Teoría de la novela española del siglo XIX, que será probablemente la exposición más completa del pensamiento de Baquero sobre la novela (lo que viene a ser lo mismo que sobre su pensamiento en general).

El pensamiento sobre la novela de Baquero se apoya en tres fuentes: la influencia de Ortega, su dedicación a la novela y el cuento español en el siglo XIX y un espíritu cervantino. A estas tres fuentes habría que añadir un rasgo más, insinuado sobre todo en su obra periodística, la creencia en la superioridad de la novela de Dostoievski en el escenario de la novela contemporánea.

El rasgo fundamental que Baquero observa en la novela es su flexibilidad. Esa flexibilidad no es compartida por ningún otro género, ni siquiera el cuento. Para autorizar esta observación Baquero recurre a Baroja, que había hablado en algunos prólogos de sus novelas a la permeabilidad del género. Esa flexibilidad permite los entrecruzamientos genéricos que se observan en la novela. Muestras de esos cruces de géneros son las combinaciones de novela y poesía que aparecen en las obras de Cervantes, Clarín (se refiere a Doña Berta) y Pérez de Ayala. Las nivolas de Unamuno le sirven para ejemplificar la rigidez de la crítica que se empeña en diseñar un esquema convencional para la novela.

Baquero repasa los varios conceptos que se han empleado en el afán crítico de definir la novela (narración, descripción, presentación, ficción, realismo...) y en todos ellos encuentra su insuficiencia para comprender los fenómenos novelísticos. Sólo pueden dar cuenta de aspectos parciales. También contrasta la novela con lo que denomina géneros afines - la novella y el cuento- y concluye que estos se aproximan más a la poesía que a la novela. La razón de esta proximidad es el efecto único, dicho en términos de E. A. Poe. Baquero lo explica como «una nota emocional emitida de una sola vez». 
Pero que no sirvan las definiciones formales de la novela no significa que no sea posible y necesario comprender el género. Esa comprensión ha de ser necesariamente histórica, evolutiva y se ha de expresar en una tipología que dé cuenta de la evolución histórica. Baquero acepta este reto y ofrece algunas conclusiones dispersas y, quizás, provisionales. En Qué es la novela esa tipología se reparte por los capítulos dedicados a los tipos, temas y técnicas de la novela. La tipología provisional comienza por señalar dos grandes corrientes de la novela: novela de acción y novela psicológica, siguiendo la estela de Ortega. Una aproximación al mapa conceptual de la novela ofrece las siguientes variantes: novela de aventuras, novela novelesca (en la que se funden la aventura y la psicología, como ocurre en novelas de Conrad y Green), novela de viajes (espacial, como Tom Jones y Ulises), novela de personaje (que parece identificar con la novela de tesis), novela simbólica (Kafka, Camus), novela ensayo o humanística (Mann), novela filosófica (Sartre, La náusea). Esta primera tipología se complementa con ramificaciones temáticas: pastoral o rural, histórica, futurista, erótica, humorística, católica, testimonio, radiofónica, policíaca... Incluso, al plantearse el problema de las técnicas, encuentra la novela epistolar.

Estos tanteos deben tomarse como una hipótesis de trabajo todavía no consolidada. Esa consolidación debería venir de la mano de un estudio de la evolución histórica de la novela basado en una filosofía de la historia. Hacia esa meta apunta Baquero aunque le faltara tiempo para alcanzarla ${ }^{5}$.

Otros aspectos de la aproximación a la novela de Baquero resultan especialmente significativos. Enumeraré algunos. El primero es la desconfianza con la que Baquero trata «el equívoco concepto de realismo» $(1966,51)^{6}$. El recelo hacia ese concepto le lleva a cuestionar el realismo de Balzac. En su estudio «Cervantes, Balzac y la voz del narrador» inserta un capítulo titulado «¿Balzac, realista?» del que se deduce que la estética balzaciana se orienta hacia el simbolismo en términos parecidos a los que utilizara Bergamín (1972, 164-67). La contención con que se expresa Baquero le impide llegar a establecer que el realismo es una falacia crítica, pero en sus artículos ofrece indicios de pensar así. Entre otros indicios cabe señalar su predilección por novelistas como Pérez de Ayala. Un segundo aspecto es su rechazo de la idea tópica que remite la novela (e incluso el cuento) al mundo de la poesía épica. Esta creencia suele llevar a calificar la novela de degeneración de la épica. Para Baquero es una consecuencia del peso de la vieja preceptiva en el pen-

${ }^{5}$ La limitación del estudio evolutivo de la novela llevó a Baquero al campo del estructuralismo. Con la concepción estructuralista de la novela parece alcanzar un atajo a la exposición de una filosofía de la historia literaria. Esto ocurre en su obra más difundida Estructuras de la novela actual (1989).

${ }^{6}$ En «Viejo y nuevo realismo novelesco» Baquero expresa su escepticismo sobre la categoría del realismo y su derivado el realismo español. Este realismo es «un comodín que apenas dice nada» $(2006,263)$. 
samiento literario moderno (1992, 180-81). Baquero concibe la novela como un género nuevo. Se sitúa en una línea de pensamiento que tiene su primer representante en G. B. Giraldi Cintio, en el siglo XVI, y su culminación en la obra de M. Bajtín. El último aspecto y, quizá, el más llamativo del pensamiento de Baquero es su filiación orteguiana. Esta filiación no es un mero epigonismo. Tiene dos facetas: en la primera representa la continuidad de las ideas orteguianas sobre la novela y la estética. Ya Ortega había enterrado el realismo una noche en el Père Lachaise, de la mano de Bouvard y Pècuchet. La segunda faceta tiene que ver con el núcleo central del pensamiento de Ortega. Se puede resumir en los conceptos centrales para la investigación novelística de Baquero: perspectivismo y contraste, en primer lugar; tragicomedia, esto es, la mezcla de lo serio y la risa, del bien y del mal, en segundo lugar. Pero esta continuidad orteguiana de Baquero contiene un matiz peculiar: su cervantismo, lo que podríamos llamar simplemente grandeza de espíritu, superación de todo unilateralismo. Quizá quien mejor haya captado esa dimensión esencial del pensamiento de Baquero sea su discípulo Antonio García Berrio. García Berrio ha llamado al pensamiento de Baquero crítica ética, una crítica que no es divagación moralista sino crítica estética y cultural, fundada en la estética cervantina (XI-XII). García Berrio ha llamado la atención sobre la profunda influencia del espíritu cervantino en esa crítica ética. También ha observado que tal crítica tiene su expresión estética en una extraordinaria sensibilidad para el simbolismo. En efecto, en el artículo «Oscuridad y simbolismo» encontramos una apretada síntesis de lo que podría haber sido la teoría del simbolismo de Baquero (2006, 73-75). «El simbolismo medieval —estructurado tantas veces en la amplia orquestación de la alegoría- es unívoco y no admite (...) posibilidad alguna de confusión (...) Son — los medievalessímbolos declarados o fácilmente interpretables». Más vagorosidad hay en los románticos - Espronceda y Bécquer- pero con una alusión tan vibrante y enfática que no ofrece lugar a dudas. En cambio, en Kafka aprecia Baquero un simbolismo literario plurivalente, caracterizado por la multiplicidad de las posibles interpretaciones. Esto lleva al hermetismo —entendido en un sentido orteguiano - o, al menos, a la plurivocidad. Melville, Henry James y Faulkner constituyen otros ejemplos de ese simbolismo variable y transcendente. «Oscuridad y simbolismo, concluye, cuentan y pesan en la literatura de hoy, tal vez como cifra o signo de la compleja problemática del hombre actual».

Sobre este fundamento teórico simbolista hay que situar la admiración de Baquero por Dostoievski. A propósito de Henry James escribe: «A veces Henry James, por algunos temas que trata, produce casi el efecto de un Dostoievski en tono menor, un Dostoievski anglosajón capaz de crear seres complicados y aun morbosos, pero carentes de la trágica crispación que es característica de unos Karamázov o un Raskólnikov» (2006, 91).

Y no falta en el pensamiento de Baquero un utopismo amable. A propósito de los escritores que anticipan una época o un espíritu aun por venir, 
concluye que se trata de relaciones de hermandad que se dan en la creación artística y que son los signos universales del diálogo y entendimiento entre humanos, «de una no decaída aspiración (aunque muy herida y combatida esperanza) hacia un mejor futuro para toda la humanidad» $(2006,163)$.

\section{LA MANERA ESPAÑOLA DE VER LAS COSAS}

Quizá el lector de este modesto estudio haya llegado ya a la conclusión de que su autor ha retomado la manera española de ver las cosas, que persiguiera en su día Ortega. En verdad, el autor de este estudio no cree que exista tal manera patriótica. No se interesa por una estética española, sencillamente porque no cree que la estética pueda encerrarse en fronteras nacionales.

Pero, con los argumentos expuestos hasta aquí en la mano, parece incuestionable que ha habido una trayectoria entre pensadores españoles profunda y coherente en lo que se refiere a la estética de la novela. Puede objetarse que Ortega, a la hora de interpretar a Baroja, no se atuvo al espíritu de la «Meditación primera», al menos en toda la extensión de lo expuesto en ella. Las implacables cualidades visionarias de Bergamín tampoco destacaron por su productividad. Incluso, el sutil aliento intelectual de Baquero hizo importantes concesiones al espíritu emergente del estructuralismo al punto de que han teñido su imagen actual de reminiscencias estructurales. Todo eso es cierto, pero no es lo esencial. Lo esencial, a mi juicio, es que el hilo de la mejor estética de la novela ha hilvanado el pensamiento de estos autores para ofrecer un perfil con mayor alcance de futuro que de presente, y no digamos de pasado. Ese hilo estético se ha elaborado sobre las lecciones del cervantismo y de la dostoievskina. Esto quiere decir que las hebras de ese hilo provienen del gran simbolismo humorístico y de sus lecciones. Y, quizá, quiera decir también que ese hilo debe tener continuidad, la continuidad de seguir tejiendo una estética de la novela que dé salida a las lecciones acumuladas y, parcialmente, olvidadas.

\section{REFERENCIAS BIBLIOGRÁFICAS}

BAQUERO GOYANES, Mariano. Qué es la novela. $2^{\mathrm{a}}$ ed. Buenos Aires: Columba, 1966.

-. El cuento español. Del romanticismo al realismo. Madrid: CSIC, 1992.

—. Estructuras de la novela actual. Madrid: Castalia, 1989.

- Variaciones sobre un mismo tema (Artículos de prensa). Esteve, Abraham y Gómez, Francisco Vicente (eds.). Murcia: Universidad de Murcia, 2006.

BERGAMÍN, José. «Laberinto de la novela y monstruo de la novelería. Cervantes y Dostoievski». Beltenebros y otros ensayos de Literatura Española. Barcelona: Noguer, 1973, pp. 77-139.

GARCÍA BERRIO, Antonio. «Memoria crítica de Mariano Baquero». En: BAQUERO GOYANES, Mariano (ed.). Variaciones sobre un mismo tema. IX-LIV. 
ORTEGA Y GASSET, José. Meditaciones sobre la literatura y el arte (La manera española de ver las cosas). Inman Fox, E. (ed.). Madrid: Castalia, 1988.

—. «Ideas sobre el teatro y la novela». Revista de Occidente. Madrid: Alianza Editorial, 1982. ORRINGER, Nelson R. Ortega y sus fuentes germánicas. Madrid: Gredos, 1979.

Fecha de recepción: 17 de diciembre de 2007

Fecha de aceptación: 25 de junio de 2008 